\title{
Cadaveric dissection- An integral part of first year MBBS anatomy teaching (students' perspective)
}

\author{
Pratik N. Trivedi ${ }^{1}$, Mohit V. Changani ${ }^{2, *}$, Ashish J. Rathwa ${ }^{3}$, Chintan J. Lakhani ${ }^{4}$ \\ ${ }^{1,3,4}$ Tutor, ${ }^{2}$ Assistant Professor, Dept. of Anatomy, ${ }^{1,2,4}$ GMERS Medical College, Junagadh, Gujarat, 3PDU Medical College, \\ Rajkot, Gujarat, India
}

*Corresponding Author:

Email: mohit402@gmail.com

Received: $31^{\text {st }}$ January, 2018

Accepted: $10^{\text {th }}$ March, 2018

\begin{abstract}
Introduction: Cadaveric dissection has been the integral part of the first year anatomy teaching since long back. With advancing technologies in the medical field, many teaching aids have been provided to replace the dissection.

Objective: To investigate and understand the perceptions of undergraduate medical students towards the cadaveric dissection and its psychological and emotional impacts.

Material and Methods: Two sets of questionnaires were prepared. These questionnaires were circulated through 283 medical students and their responses were recorded.

Observations and Results: It was observed in the study that $97.2 \%$ students were of opinion that cadaveric dissection is an integral part of first year anatomy teaching while $91.2 \%$ student believed that cadaveric dissection is preferable to other practical anatomy teaching aids.

Conclusion: It concludes that cadaveric dissection is an important part of medical curriculum. Cadaveric dissection is also the best method for learning of anatomy. Though prosected specimens, plastic models, plastinated specimens etc. will be helpful in learning of anatomy, cadaveric dissection should be the basic part of anatomy learning.
\end{abstract}

Keywords: Dissection, Cadaver, First year MBBS.

\section{Introduction}

Anatomy is the first subject offered to the undergraduate medical and dental students in India. It is considered as the backbone of all medical sciences (Turney 2007). The term anatomy is derived from the Latin word 'anatome', which means cut up or cut open. Apart from routine theory classes, cadaver dissection is essential in learning the anatomy. Dissection is considered to provide hands-on view of the human body and also helps the students to be accustomed to the human body. It is a fact that medical or surgical success could only be based on exact knowledge of the human anatomy, which is derived from the cadaver dissection (Cahil 2009). Hence, cadaver dissection is considered of pivotal importance during medical studies.

It is probably the first time that undergraduate students come into close contact with human cadavers during the dissection. And so, the dissection hall brings in many psychological and emotional challenges to a large number of these students. The impact of first exposure to human cadavers along with physical, psychological, and emotional effects have been documented in a few studies (Parker 2002, Older 2004, Patel 2008, Mulu 2010, Mishra 2015). Therefore the objective of this study was to investigate and understand the perceptions of undergraduate medical students towards the first cadaveric dissection and its psychological and emotional impacts.

\section{Materials and Methods}

The present study is a cross sectional study with detailed structured performa of questionnaires. An approval from the Ethics Committee was not required for such type of study. A consent was obtained from the participating undergraduate students at GMERS Medical College, Junagadh. Based on the review of literature and similar studies, a 32-item questionnaire was designed that contained demographic information and physical, psychological, and emotional reactions during first exposure to human cadavers. The questionnaire was circulated to 283 first-year students at the participating institutes through an online cloud format (Google Documents). Students were provided with background of the study, instructions on the questionnaire, and how to fill appropriate option for each item.

\section{Observations and Results}

The gender distribution was equal with 155 (54.8\%) male and 128 (45.2\%) female participants. The results of the study have been shown in the table 1 and table 2. Of 283 participants, 114 (40.3\%) had seen a dead body prior to first dissection session, primarily male participants (71 [62.3\%]).

General observations or perceptions prior to first dissection session: $135(47.7 \%)$ participants did not 
find the entry to dissection hall pleasant, of which 71 were male and 64 were female.

$29(10.2 \%)$ participants had fear or stress in the dissection hall, of which 12 were male and 17 were female.

Below observations were reported during or following the first dissection session:

Physical reactions:

$23(8.1 \%)$ participants experienced nausea, of which 12 were male and 11 were female.

$8(2.8 \%)$ participants experienced vomiting, of which 1 was male and 7 were female.

45 (15.9\%) participants experienced headache, of which 24 were male and 21 were female.

$21(7.4 \%)$ participants experienced weakness, of which 4 were male and 17 were female.

$15(5.3 \%)$ participants experienced dizziness, of which 3 were male and 12 were female.

\section{Psychological and emotional reactions:}

$21(7.4 \%)$ participants experienced fear, of which 7 were male and 14 were female.

$22(7.8 \%)$ participants experienced restlessness, of which 9 were male and 13 were female.

32 (11.3) participants experienced lack of concentration, of which 16 were male and 16 were female.

$6(2.1 \%)$ participants experienced nightmares, all of which were female.

$30(10.6 \%)$ participants experienced shivering, of which 15 were male and 15 were female.

$19(6.7 \%)$ participants experienced influence on routine activities, of which 9 were male and 10 were female.

$49(17.3 \%)$ participants experienced difficulties in consuming food, of which 18 were male and 31 were female.

$7(2.4 \%)$ participants experienced sleep disturbance, of which 3 were male and 4 were female.

$49(17.3 \%)$ participants experienced difficulties in breathing, of which 25 were male and 24 were female.
$122(43.1 \%)$ participants hesitated in handling the human cadaver for the first time, of which 66 were male and 56 were female.

$16(5.6 \%)$ participants reported unpleasant feelings while holding the bone during osteology demonstration, of which 9 were male and 7 were female.

$63(22.3 \%)$ participants had recurrent thoughts of human cadaver after the first encounter, of which 34 were male and 29 were female.

121 (42.7) participants experienced formalin odor after the first encounter with human cadaver and leaving the college, of which 52 were male and 69 were female.

$250(88.3 \%)$ participants reported that dissection enhanced their thinking in a logical manner, of which 128 were male and 122 were female.

$256(90.4 \%)$ participants favoured that cadaver dissection was ethically acceptable to them, of which 143 were male and 113 were female.

$275(97.2 \%)$ participants assented that cadaver dissection was an important part of the undergraduate medical curriculum, of which 148 were male and 127 were female.

$209(73.8 \%)$ participants felt that interaction with anatomy staff before entering the dissection hall would lessen the emotional impact of the first cadaver encounter, of which 116 were male and 93 were female. $269(95.0 \%)$ participants favoured cadaver dissection over prospected specimen demonstration, of which 146 were male and 123 were female.

$258(91.2 \%)$ participants disagreed on any alternate future techniques to replace cadaver dissection, ie, plastic models, computer assisted training. Of these participants, 137 were male and 121 were female.

$274(96.8 \%)$ participants felt gratitude towards the body donors, of which 148 were male and 126 were female.

$18(6.3 \%)$ participants thought to leave the study after exposure to human cadaver, of which 13 were male and 5 were female.

Table 1: Questionaries 1 and Students' feedback

\begin{tabular}{|c|l|c|c|}
\hline No. & \multicolumn{1}{|c|}{ Questions } & \multicolumn{2}{c|}{ Response } \\
\cline { 3 - 4 } & & Yes (\%) & No (\%) \\
\hline 1 & Have you ever seen a dead body before? & 40.3 & 59.7 \\
\hline 2 & $\begin{array}{l}\text { Did you have pleasant feeling at the time } \\
\text { of entering the dissection hall? }\end{array}$ & 52.3 & 47.7 \\
\hline 3 & $\begin{array}{l}\text { Have you ever had any fear or stress in the } \\
\text { dissection hall? }\end{array}$ & 10.2 & 89.8 \\
\hline 4 & $\begin{array}{l}\text { Did you ever have recurrent thoughts of } \\
\text { cadavers after the first encounter with } \\
\text { cadaver? }\end{array}$ & 22.3 & 77.7 \\
\hline 5 & $\begin{array}{l}\text { Did you ever have the experience of } \\
\text { formalin odour after your first encounter } \\
\text { with cadaver when you are away from } \\
\text { college? }\end{array}$ & 42.8 & 57.2 \\
\hline 6 & $\begin{array}{l}\text { Did you like to hold the bone during } \\
\text { osteology demonstrations? }\end{array}$ & 8.7 & 94.3 \\
\hline
\end{tabular}




\begin{tabular}{|c|c|c|c|}
\hline 7 & $\begin{array}{l}\text { Do you have any apprehension (hesitation) } \\
\text { in handling the cadaver directly for the } \\
\text { first time? }\end{array}$ & 43.1 & 56.9 \\
\hline 8 & $\begin{array}{l}\text { Do you think that dissection enhances the } \\
\text { thinking in a logical manner? }\end{array}$ & 88.3 & 11.7 \\
\hline 9 & Is cadaver dissection ethically acceptable? & 90.5 & 9.5 \\
\hline 10 & $\begin{array}{l}\text { Do you feel that anatomy dissection is an } \\
\text { important part of undergraduate medical } \\
\text { curriculum? }\end{array}$ & 97.2 & 2.8 \\
\hline 11 & $\begin{array}{l}\text { Do you feel that interaction with the } \\
\text { anatomy staff before entering the } \\
\text { dissection hall would lessen the emotional } \\
\text { impact of the first encounter? }\end{array}$ & 73.9 & 26.1 \\
\hline 12 & $\begin{array}{l}\text { Does cadaver dissection give better results } \\
\text { than demonstration on prosected } \\
\text { specimens? }\end{array}$ & 95.1 & 4.9 \\
\hline 13 & $\begin{array}{l}\text { Should cadaver dissection techniques be } \\
\text { replaced by plastic models, computer } \\
\text { assisted training etc in near future? }\end{array}$ & 8.8 & 91.2 \\
\hline 14 & $\begin{array}{l}\text { Do you feel any sense of gratitude to } \\
\text { people who donated their bodies? }\end{array}$ & 96.8 & 3.2 \\
\hline 15 & $\begin{array}{l}\text { Do you find dissection enjoyable/ } \\
\text { fascinating / interesting? }\end{array}$ & 94.0 & 6.0 \\
\hline 16 & $\begin{array}{l}\text { Did you feel any hesitancy in dissecting } \\
\text { without gloves? }\end{array}$ & 53.7 & 46.3 \\
\hline 17 & $\begin{array}{l}\text { Did you have the thought to leave the } \\
\text { medical course after cadaveric exposure? }\end{array}$ & 6.4 & 93.6 \\
\hline 18 & $\begin{array}{l}\text { Have you even been injured by the } \\
\text { dissecting instruments? }\end{array}$ & 38.5 & 61.5 \\
\hline
\end{tabular}

Table 2: Questionnaires 2 and Students' feedback

\begin{tabular}{|c|l|c|c|}
\hline \multirow{2}{*}{ No } & \multicolumn{1}{|c|}{ Symptoms } & \multicolumn{2}{c|}{ Response } \\
\cline { 3 - 4 } & & Yes (\%) & No (\%) \\
\hline 1 & Nausea & 8.1 & 91.9 \\
\hline 2 & Vomiting & 2.8 & 97.2 \\
\hline 3 & Headache & 75.9 & 84.1 \\
\hline 4 & Weakness & 5.3 & 92.6 \\
\hline 5 & Dizziness & 7.4 & 94.7 \\
\hline 6 & Fear & 7.8 & 92.6 \\
\hline 7 & Restlessness & 11.3 & 82.2 \\
\hline 8 & Lack of concentration & 2.1 & 97.7 \\
\hline 9 & Nightmares & 10.6 & 89.4 \\
\hline 10 & Shivering of hands & 6.7 & 93.3 \\
\hline 11 & Influence on routine activities & 17.3 & 82.7 \\
\hline 12 & Difficulty in consuming food & 2.5 & 97.5 \\
\hline 13 & Sleep disturbances & 17.3 & 82.7 \\
\hline 14 & Difficulty in breathing & & \\
\hline
\end{tabular}

\section{Discussion}

Cadaveric dissection is a basic step for medical curriculum. An actual hand on training on cadaveric dissection will help in learning and skill procedure. But cadaver and chemical used for preservation of cadaver like formaldehyde have some effects on medical students. Here, we discuss about reviews of medical students on importance of cadaveric dissection and some unpleasant effects of chemicals.

97.2\% participants have stated that cadaveric dissection has an important role in undergraduate medical curriculum. And studies of Agnihotri G \& Sagoo MG (2010) (78.33\%), Dubhashi S et al (2011) (67\%), Mishra P et al (2015) (83.3\%), Khan AS et al (2014) (80\%) \& Singroha R et al (2015) (97.79\%) also support this statement. 
In our study, 95\% participants reviewed that cadaveric dissection over prosected specimen. While Agnihotri G \& Sagoo MG (2010) (83.66\%), Somnath D et al (2015) (94\%), N A Rajeh et al. (2016) (81\%) had found similar thought of participants. $91.2 \%$ participants disagreed on any alternate future techniques to replace cadaver dissection, i.e., plastic models, computer assisted training. Of these participants, 137 were male and 121 were female but in study of N A Rajeh et al. (2016), 36.6\% female participants thought that dissection of cadaver can be substituted by plastic models, computer based training programs etc. in future.

In present study, $88.3 \%$ participants reported that dissection enhanced their thinking in a logical manner that same as Agnihotri G \& Sagoo MG (2010) (90\%) \& Saha $\mathrm{N}$ et al (2015) (98\%). In our study, only $10.2 \%$ participants had fear or stress prior to first dissection session while Agnihotri G \& Sagoo MG (2010) had found that $86.66 \%$ participants had any fear or stress.

Only $8.1 \%$ participants experienced nausea during dissection similar as studies of Singroha $\mathrm{R}$ et al (2015) (6.63\%), Vinay kumar V et al (2015) (3.3\%) \& Saha N et al (2015) (8.1\%) while Hemlatha NR et al (2015) shown $24 \%$ participants had symptoms of nausea.

Headache was experienced by $15.9 \%$ participants of present study while $26.8 \%$ participants had headache in study of Hemlatha NR et al (2015). Nightmares experienced by only $2.1 \%$ participants in present study almost same as study of Naz $\mathrm{S}$ et al (2011) (7.4\%) \& Singroha R et al (2015) (3.87\%) while Dubhashi $\mathrm{S}$ et al (2011) shown $45 \%$ participants had horrifying dreams.

The cadaveric dissection remains the most effective method for learning anatomy. The new generation of students which are more advanced in technology usage are also of same opinion. They newer methodologies for anatomy learning can be included as complementary modalities but not a dissection replacement.

\section{Conclusion}

It concludes that cadaveric dissection is an important part of medical curriculum. Cadaveric dissection is also the best method for learning of anatomy. It was concluded that though some students felt some physical as well as psychological symptoms at the first encounter of cadavers, majority of the students felt cadaveric dissection as an unreplaceable teaching aid. The first encounter could be made less eventful by prior discussion with the college teaching staff. Though prosected specimens, plastic models, plastinated specimens etc. will be helpful in learning of anatomy, cadaveric dissection should be the basic part of anatomy learning. There are some physical and psychological effects of formaldehyde and cadaver on medical students. We can overcome these effects by other chemicals and counselling. With this results and analysis, it could be concluded that human cadaveric dissection is the unreplaceable modality for teaching anatomy. In order to decrease the unpleasant events and health effects, further studies regarding "how to decrease / alleviate those effects" are needed.

\section{References}

1. Agnihotri G, Sagoo MS. Reactions of first year Indian medical students to the dissection hall experience. NJIRM. 2010;1(4):4-9.

2. Cahill KC, Ettarh RR. Attitudes to anatomy dissection in an Irish medical school. Clin Anat. 2009; 22(3):386-91.

3. Dubhashi S, Dubhashi U, Singh A, Trinath T. Medical students react to cadaveric dissections. Rec Res Sci Tech. 2011;3(1):135-8.

4. Hemalath NR, Samaga MP. Acute symptoms experienced by medical students on first exposure to formalin in dissection hall. IJSRE,2015;3(4):3205-09.

5. Khan AN, Baig S, Zian S. Importance off cadaveric dissection in learning gross anatomy. Pakistan journal of Medicine and Dentistry, 2014;3(4):31-5.

6. Mishra P, Ksheersagar DD, Mishra D. Attitude of first year medical students towards dissection. J Cont Med A Dent. 2015;3(1):45-9.

7. Mulu N, Tegabu D. Medical Students' Attitudinal Changes Towards Cadaver Dissection: A Longitudinal Study. Ethiop J Health Sci. 2012;22(1):51-8.

8. Naz S, Nazir G, Iram S, Mohammad M, Umair, Qari IH et al. perceptions of cadaveric dissection in anatomy teaching. J Ayub Med Coll Abottabad 2011;23(3):145-8.

9. Older J. Anatomy: a must for teaching the next generation.Surgeon.2004;2(2):79-90.

10. Parker LM, What's wrong with the dead body? Use of the human cadaver in medical education. Med J Aust. 2002;176(2):74-6.

11. Patel KM, Moxham BJ. The relationships between learning outcomes and methods of teaching anatomy as perceived by professional anatomists. Clin Anat. 2008;21(2):182-9.

12. Rajeh NA, et al., Cadaver dissection: A positive experience among Saudi female medical students, Journal of Taibah University Medical Sciences (2016),1-5.

13. Saha N, Chaudhuri S, Singh Mm. Attitude of first year medical students in dissection hall. IOSR-JDMS, 2015;14(5):74-8.

14. Singroha R, Verma U, Chhbra S. Introduction to cadavers - a student's perspective. IAIM, 2015;2(3):134-41.

15. Somanath D, Srivastava S, Rajasekar SS. Experience in anatomy lab - an analysis in preclinical students. International $\mathrm{J}$ of Healthcare and Biomedical Research, 2015;3(2):117-21.

16. Turney BW. Anatomy in a modern medical curriculum. Ann R Coll Surg. 2007; 89(2):104-7.

17. Vinay Kumar V et al. Attitude of first year Indian medical students towards cadaver dissection. Int $\mathrm{J}$ Anat Res 2015,3(3):1255-58. 